\title{
Pengaruh Online Customer Review dan Kepercayaan terhadap Minat Beli pada Marketplace Lazada
}

\author{
Eka Syarifah $^{\varpi_{1}}$, Karyaningsih ${ }^{2}$ \\ 1,2,3 Universitas Singaperbangsa Karawang \\ DOI : https://doi.org/10.37531/ecotal.v2i2.87
}

\begin{abstract}
ABSTRAK
Penelitian ini bertujuan untuk menguji pengaruh Online Customer Review dan Kepercayaan terhadap Minat Beli pada Marketplace Lazada. Penelitian dilakukan dengan menggunakan metode deskriptif dan verifikatif, yaitu mengumpulkan, menyajikan, menganalisis dan melakukan pengujian hipotesis serta membuat kesimpulan dan saran. Sampel dikumpulkan dengan menggunakan metode slovin dengan teknik nonprobability sampling dengan purposive sampling yang kemudian menghasilkan 100 sampel dari populasi yang ada. Hasil penelitian menunjukkan bahwa terdapat korelasi yang cukup kuat dan signifikan antara online customer review dan kepercayaan, variabel online customer review dan kepercayaan secara parsial berpengaruh positif dan signifikan terhadap minat beli, serta variabel online customer review dan kepercayaan secara simultan berpengaruh positif dan signifikan terhadap minat beli.
\end{abstract}

\section{Kata Kunci :}

Online Customer Review, Kepercayaan, Minat Beli

\begin{abstract}
Abstrak : This study aims to examine the effect of Online Customer Review and Trust on Buying Interest on the Lazada Marketplace. The research was conducted using descriptive and verification methods, namely collecting, presenting, analyzing and testing hypotheses and making conclusions and suggestions. Samples were collected using the slovin method with nonprobability sampling technique with purposive sampling which then produced 100 samples from the existing population. The results show that there is a fairly strong and significant correlation between online customer review and trust, online customer review and trust variables partially have a positive and significant effect on buying interest, and online customer review and trust variables simultaneously have a positive and significant effect on buying interest. Keywords : Online Customer Review, Trust, Buying Interest.

\footnotetext{
$\triangle$ Corresponding Author :

E-mail address: eka.syarifah17073@student.unsika.ac.id (Jl. HS.Ronggo Waluyo, Puseurjaya., Kabupaten Karawang) “Received 18 Februari 2021, Accepted 13 Juni 2021, Published 07 Juli 2021"
} 


\section{Pendahuluan}

Perkembangan teknologi informasi pada era globalisasi sedang mengalami perkembangan pesat, khususnya media internet. Pengguna internet di Indonesia mengalami peningkatan yang sangat signifikan pada setiap tahunnya. Begitupula pada pengguna e-commerce di Indonesia, tren pengguna e-commerce di Indonesia meningkat signifikan dalam beberapa tahun terakhir (databooks.katadata.com diakses pada tanggal 11 Februari 2021 pukul 21.54 WIB)

Bisnis e-commerce merupakan kegiatan jual beli secara online. Perkembangan e-commerce saat ini terus meningkat setiap tahunnya. Salah satu platform yang paling banyak digunakan dalam aktivitas jual beli tersebut adalah marketplace. Saat ini terdapat banyak marketplace di Indonesia dengan jumlah pengunjung yang cukup tinggi. sehingga hal ini menunjukkan minat terhadap berbagai marketplace yang ada. (Sri Damayanti, 2019). Beberapa marketplace seperti Shopee, Tokopedia, Bukalapak, Lazada, Blibli.com saat ini saling bersaing. Salah satu aplikasi marketplace yang banyak digunakan adalah Lazada. (Arbaini, 2020).

Menurut data yang dihimpun oleh IPrice (2020), Lazada masuk dalam lima besar e-commerce terpopuler di Indonesia. Statistik kunjungan aplikasi mobile e-commerce Indonesia menunjukkan bahwa Lazada menempati peringkat keempat terbanyak pengunjung aplikasi mobile e-comemerce bulanan pada kuartal 4 tahun 2020 serta ranking ketiga pada AppStore dan ranking ketiga pada PlayStore masih tertinggal jauh dibawah Shopee, Tokopedia dan Bukalapak.

Tabel 1. Statistik Kunjungan Dan Ranking Aplikasi Mobile Untuk E-Commerce Indonesia Kuartal 4 tahun 2020

\begin{tabular}{ccccc}
\hline NO. & Market Place & $\begin{array}{c}\text { Pengunjung Web } \\
\text { Bulanan }\end{array}$ & $\begin{array}{c}\text { Ranking } \\
\text { AppStore }\end{array}$ & $\begin{array}{c}\text { Ranking } \\
\text { PlayStore }\end{array}$ \\
\hline 1. & Shopee & 129.320 .800 & 1 & 1 \\
\hline 2. & Tokopedia & 114.655 .600 & 2 & 4 \\
\hline 3. & Bukalapak & 38.583 .100 & 7 & 7 \\
\hline $\mathbf{4 .}$ & Lazada & $\mathbf{3 6 . 2 6 0 . 6 0 0}$ & $\mathbf{3}$ & $\mathbf{3}$ \\
\hline 5. & Blibli & 22.413 .100 & 6 & 5 \\
\hline
\end{tabular}


Sumber : iprice.co.id (2020) (diakses pada 12 Februari 2021, Pukul 20:45 WIB)

Semakin maraknya bisnis internet tentunya persaingan di dunia bisnis online akan semakin ketat, sehingga dapat menjadi ancaman bagi para pengusaha atau pebisnis yang sudah ada sehingga dapat berpindah konsumen dari satu situs ke situs lainnya. Persaingan tersebut tentu menjadi ancaman bagi Lazada, mengingat Lazada merupakan salah satu dalam lima besar e-commerce terpopuler di Indonesia. Terdapat fenomena negatif yang ditunjukan oleh adanya penurunan jumlah pengunjung situs Lazada pada beberapa tahun terakhir. Jumlah pengunjung pada website Lazada cenderung menurun jumlah pengakses sepanjang 3 tahun terakhir.

Tabel 2. Pengunjung Web Lazada

\begin{tabular}{cc}
\hline Pengunjung Web & Tahun \\
\hline 58.288 .400 & Q4 2018 \\
\hline 52.044 .500 & Q1 2019 \\
\hline 49.620 .200 & Q2 2019 \\
\hline 27.995 .900 & Q3 2019 \\
\hline 28.383 .300 & Q4 2019 \\
\hline 24.400 .000 & Q1 2020 \\
\hline 22.021 .800 & Q2 2020 \\
\hline 22.674 .700 & Q3 2020 \\
\hline 36.260 .600 & Q4 2020 \\
\hline
\end{tabular}

Sumber : iprice.co.id , 2020 (diakses pada 12 Februari 2021, Pukul 20:45 WIB)

Berdasarkan dari data yang terdapat pada Iprice, Lazada mengalami penurunan jumlah pengunjung pada beberapa tahun terakhir. Pada tahun 2018 kuartal keempat sampai dengan tahun 2019 kuartal ketiga Lazada mengalami penururan pengunjung web yang signifikan, dari 58.288.400 pengguna menjadi 27.995.900 pengguna, namun pada tahun 2019 kuartal empat pengunjung web Lazada mengalami peningkatan tetapi tidak terlalu signifikan, dan selanjutnya pada tahun 2020 kuartal satu dan dua mengalami penurunan kembali menjadi 22.021.800 pengguna dan pada kuartal tiga dan empat mengalami peningkatan jumlah pengunjung namun tidak signifikan seperti halnya pada tahun 2018. 
Penurunan jumlah pengunjung tersebut disebabkan oleh adanya beberapa keluhan konsumen yang ditunjukan pada fitur online review yang ada pada Lazada. Dilansir dari (priceprice.com, 2020), menunjukan adanya beberapa review yang buruk yang diberikan konsumen karena ketidaksesuaian dan ketidakpuasan atas produk atau pelayanan yang mereka terima. Review buruk tersebut dapat menurunkan minat beli pada Marketplace Lazada itu sendiri. Sebaliknya jika terdapat review positif maka akan meningkatkan minat beli tersebut.

Hal tersebut sesuai dengan penelitian yang menyatakan bahwa faktor yang mempengaruhi minat beli konsumen salah satunya adalah online consumer review and rating (Ichsan et al.,2018) Consumer review merupakan suatu pendapat atau pengalaman yang diberikan konsumen dari pelayanan atau produk bisnis yang diperolehnya.

Selain Online Customer Review Cara untuk menarik minat konsumen agar berkunjung dan melakukan transaksi melalui situs tersebut, maka suatu perusahaan harus membangun kepercayaan yang tinggi terhadap calon konsumen, pernyataan tersebut relevan dengan penelitian yang dilakukan oleh (Tilaar et al., 2018) yang Menunjukan bahwa kepercayaan berpengaruh signifikan terhadap Minat Beli Online. Kepercayaan konsumen mengacu pada keyakinan bahwa orang tertentu memiliki integritas dan dapat dipercaya, dan bahwa orang yang dipercaya akan memenuhi semua kewajiban dalam bertransaksi sesuai dengan yang diharapkan (Khotimah \& Febriansyah, 2018).

Dilansir dari mediakonsumen.com dimana ada seorang konsumen yang mengeluhkan bahwa dirinya ditipu oleh salah satu online shopping di Lazada, berupa produk yang tidak dikirim oleh penjual, kualitas produk tidak baik, produk tidak sesuai dengan gambar, dan lain sebagainya, (diakses pada Tanggal 17 Maret 2021, Pukul 21:00 WIB). Kasus berikutnya yaitu dimana cerita korban penipuan di Lazada, dan uang jutaan melayang yang dilansir dari https://inet.detik.com/ (diakses pada Tanggal 17 Maret 2021, Pukul 21:00 WIB), serta kasus kebocoran data, Lazada mengalami kebocoran sebanyak 1,1 juta data, kasus tersebut tentunya membuat konsumen Lazada khawatir karena ketidakamanan dalam bertransaksi secara online, dari beberapa kasus tersebut mengakibatkan menurunnya kepercayaan pada pihak Lazada. 
Sehingga faktor yang harus ditingkatkan oleh pihak Lazada yaitu Faktor trust (kepercayaan), karena dalam transaksi jual beli online kepercayaan merupakan faktor yang sangat penting, karena tidak ada transaksi secara nyata, sehingga harus memiliki rasa percaya antar kedua belah pihak baik dari pihak pembeli maupun penjual agar transaksi jual beli online dapat dilakukan. Semakin tinggi kepercayaan, tentunya akan dijadikan ukuran untuk meningkatkan minat beli konsumen dalam bertransaksi online, sehingga semakin besar kepercayaan maka semakin besar pula minat beli tersebut.

Minat beli merupakan salah satu perilaku konsumen yang menunjukkan sejauh mana komitmen konsumen untuk melakukan pembelian, sehingga membangkitkan minat beli konsumen menjadi penting karena dapat menarik konsumen untuk mengambil keputusan pembelian suatu produk yang pada akhirnya akan menguntungkan perusahaan. Berdasarkan uraian latar belakang di atas maka peneliti tertarik untuk melakukan penelitian dengan judul "Pengaruh Online Customer Review dan Kepercayaan Terhadap Minat Beli pada Marketplace Lazada"

\section{Metode}

Dalam penelitian ini menggunakan metode penelitian kuantitatif, dengan pendekatan deskriptif dan verifikatif. Secara deskriptif penelitian ini bertujuan untuk memperoleh gambaran secara sistematis mengenai variabel online customer review dan kepercayaan sebagai variabel bebas dan minat beli sebagai variabel terikat. Secara verifikatif penelitian ini bertujuan untuk menguji hipotesis dengan perhitungan statistik. Populasi dalam penelitian ini adalah penduduk Karawang pengguna Marketplace Lazada. Populasi pada penelitian ini menggunakan rumus slovin pada tingkat kesalahan $10 \%$ maka sampel yang didapatkan adalah 100 orang responden dari penduduk Karawang. Teknik Sampling yang digunakan dalam penelitian ini adalah Nonprobability Sampling yaitu teknik pengambilan sampel yang tidak memberikan peluang atau kesempatan yang sama bagi setiap elemen atau anggota populasi untuk dipilih sebagai sampel (Sugiyono 2017:84). Teknik yang digunakan yaitu Purposive Sampling dimana teknik penentuan sampel dengan mempertimbangkan hal tertentu. Pertimbangannya yaitu: Masyarakat Karawang pengguna Marketplace Lazada dan yang berminat menggunakan Marketplace Lazada. 


\section{Hasil Penelitian dan Pembahasan}

\subsection{Uji Validitas dan Reliabilitas}

Agar hasil penelitian ini representatif, maka perlu dilakukan analisis validitas. Menurut Sugiyono (2017:123) secara efektif berarti instrumen dapat digunakan untuk mengukur konten pengukuran yang sebenarnya. Validitas merepresentasikan ketepatan antara data yang sebenarnya terjadi pada subjek dan data yang dapat dikumpulkan oleh peneliti.

Syarat yang harus dipenuhi menurut Sugiyono (2017:126) yaitu harus memenuhi kriteria sebagai berikut:

a. Jika $r \geq 0,30$ maka item - item pernyataan dari kuesioner adalah valid.

b. Jika $r \leq 0,30$ maka item - item pernyataan dari kuesioner dianggap tidak valid.

Tabel 3. Uji Validitas Variabel Online Customer Review $\left(X_{1}\right)$

\begin{tabular}{ccccc}
\hline Variabel & Item & r hitung & r kritis & Kriteria \\
\hline & X1.1 & 0,524 & 0,300 & Valid \\
X1.2 & 0,595 & 0,300 & Valid \\
X1.3 & 0,485 & 0,300 & Valid \\
Xnline Customer & X1.5 & 0,409 & 0,300 & Valid \\
Review $\left(X_{1}\right)$ & X1.6 & 0,5467 & 0,300 & Valid \\
& X1.7 & 0,472 & 0,300 & Valid \\
& X1.8 & 0,509 & 0,300 & Valid \\
& X1.9 & 0,451 & 0,300 & Valid \\
& X1.10 & 0,387 & 0,300 & Valid
\end{tabular}

Sumber : Hasil Pengolahan Data, 2021

Tabel 4. Uji Validitas Variabel Kepercayaan $\left(\mathrm{X}_{2}\right)$

\begin{tabular}{ccccc}
\hline Variabel & Item & r hitung & r kritis & Kriteria \\
\hline $\mathrm{X} 2.1$ & 0,724 & 0,300 & Valid \\
$\mathrm{X} 2.2$ & 0,569 & 0,300 & Valid \\
$\mathrm{X} 2.3$ & 0,570 & 0,300 & Valid \\
$\mathrm{X} 2.4$ & 0,616 & 0,300 & Valid \\
\hline
\end{tabular}




\begin{tabular}{lllll}
\hline Kepercayaan $\left(\mathrm{X}_{2}\right)$ & $\mathrm{X} 2.5$ & 0,650 & 0,300 & Valid \\
& X2.6 & 0,649 & 0,300 & Valid \\
& X2.7 & 0,545 & 0,300 & Valid \\
X2.8 & 0,528 & 0,300 & Valid \\
& X2.9 & 0,648 & 0,300 & Valid \\
\hline
\end{tabular}

Sumber : Hasil Pengolahan Data, 2021

Tabel 5. Uji Validitas Variabel Minat Beli (Y)

\begin{tabular}{ccccc}
\hline Variabel & Item & r hitung & r kritis & Kriteria \\
\hline \multirow{3}{*}{ Minat Beli (Y) } & Y.1 & 0,357 & 0,300 & Valid \\
Y.2 & 0,486 & 0,300 & Valid \\
& Y.3 & 0,365 & 0,300 & Valid \\
& Y.4 & 0,611 & 0,300 & Valid \\
Y.5 & 0,595 & 0,300 & Valid \\
& Y.7 & 0,509 & 0,300 & Valid \\
& Y.8 & 0,711 & 0,300 & Valid \\
& Y.9 & 0,453 & 0,300 & Valid \\
& Y.10 & 0,549 & 0,300 & Valid \\
& Y.11 & 0,484 & 0,300 & Valid \\
& Y.12 & 0,320 & 0,300 & Valid \\
\hline
\end{tabular}

Sumber : Hasil Pengolahan Data, 2021

Berdasarkan tabel diatas menunjukkan $r$ hitung $\geq 0,3$ dapat simpulkan bahwa keseluruhan item penyataan dari variabel Online Customer Review, Kepercayaan dan Minat beli dinyatakan valid.

\section{Uji Reliabilitas}

Tabel 6. Uji Reliabilitas

\begin{tabular}{ccccc}
\hline No & Variabel & r hitung & r tabel & Kriteria \\
\hline 1 & Online Customer Review & 0,708 & 0,600 & Reliabel \\
\hline 2 & Kepercayaan & 0,751 & 0,600 & Reliabel \\
\hline 3 & Minat Beli & 0,728 & 0,600 & Reliabel \\
\hline
\end{tabular}

Sumber : Hasil Pengolahan Data, 2021 
Tabel 6. menunjukan bahwa ketiga variabel yang diteliti dalam penelitian ini dinilai reliabel dimana masing-masing variabel memiliki nilai Cronbach's Alpha lebih dari 0,6 yang berarti bahwa alat ukur dalam penelitian ini merupakan alat ukur yang konsisten dan dapat dipercaya.

Tabel 7. Uji Normalitas

One-Sample Kolmogorov-Smirnov Test

\begin{tabular}{lll}
\hline & & $\begin{array}{l}\text { Unstandardized } \\
\text { Residual }\end{array}$ \\
\hline $\mathrm{N}$ & \multicolumn{1}{l}{ Mean } & 100 \\
\cline { 2 - 3 } & Std. Deviation & .0000000 \\
\hline Normal Parametersa, & Absolute & .0749 \\
\cline { 2 - 3 } & Positive & .065 \\
\cline { 2 - 3 } & Negative & -.079 \\
\hline Test Statistic & & .079 \\
\hline Asymp. Sig. (2-tailed) & & $.123^{c}$ \\
\hline a. Test distribution is Normal. & & \\
\hline b. Calculated from data. & & \\
\hline c. Lilliefors Significance Correction. & & \\
\hline
\end{tabular}

Sumber: Hasil Pengolahan Data SPSS, 2021

Berdasarkan Tabel 7. hasil uji normalitas diatas menunjukan bahwa semua data variabel mengikuti sebaran normal dengan memilki nilai signifikan $(\alpha)$ hitung 0,123 lebih besar dari 0,05.

\section{X1 : Online Customer Review}

Berdasarkan hasil penelitian didapatkan hasil mengenai variabel Online Customer Review pada Marketplace Lazada yang memiliki 10 indikator dengan total skor 3.898 dan rata rata skor 389,8 yang berada pada rentang 340-420 dengan kriteria setuju. Dengan demikian, Online Customer Review pada Marketplace Lazada dapat diasumsikan baik. Terdapat Indikator dengan skor tertinggi yaitu pada indikator Semakin banyak jumlah review positif maka semakin baik reputasi produk tersebut, dan indikator Percaya kepada review yang diberikan konsumen lain memiliki skor terendah pada variable Online Customer Review dengan skor 360. 


\section{X2 : Kepercayaan}

Berdasarkan hasil penelitian didapatkan hasil mengenai variabel Kepercayaan pada Marketplace Lazada yang memiliki 9 indikator dengan total skor 3.405 dengan rata-rata skor sebesar 378,3 yang berada pada rentang 340-420 dengan kriteria setuju. Dengan demikian Kepercayaan pada Marketplace Lazada dapat diasumsikan baik. Terdapat indikator yang memilki skor tertinggi yaitu pada indikator menyediakan produk yang dibutuhkan dan indikator memiliki empati terhadap konsumen yang merasa dirugikan menjadi indikator yang memiliki skor terendah pada variabel Kepercayaan dengan skor 357.

Y : Minat Beli

Berdasarkan hasil penelitian didapatkan hasil mengenai variabel Minat Beli pada Marketplace Lazada yang memilki 12 indikator dengan total skor sebesar 4.389 dengan rata-rata sebesar 365,75 yang berada pada rentang 340-420 dengan kriteria setuju. Dengan demikian, Minat Beli pada Marketplace Lazada dapat diasumsikan dalam kategori baik. Terdapat indikator yang memilki skor tertinggi yaitu pada indikator Konsumen akan mencari tahu tentang promosi yang diberikan. Sedangkan, diketahui pula skor terendah berada pada indikator konsumen lebih tertarik dengan situs tersebut dengan skor 324 .

\section{Kesimpulan}

Korelasi antara variabel bebas dengan nilai sebesar 0,488, dengan demikian korelasi antara Online Customer Review dan Kepercayaan memiliki tingkat hubungan yang cukup kuat dan dua arah karena memiliki nilai yang positif dan berada pada interval 0,40-0,599. Online Customer Review dan Kepercayaan secara parsial berpengaruh positif dan signifikan terhadap Minat Beli pada Marketplace Lazada. Berdasarkan hasil penelitian diketahui bahwa variable Kepercayaan memiliki kontribusi terhadap Minat beli lebih besar dengan nilai 28,3\%, sedangkan pada variable Online Customer Review memiliki kontribusi terhadap Minat Beli sedikit lebih rendah dibandingkan dengan variable Kepercayaan yaitu dengan nilai $25 \%$. Terdapat pengaruh simultan antara Online Customer Review dan Kepercayaan Terhadap Minat Beli sebesari $53,3 \%$ dan sisanya sebesar $46,7 \%$ merupakan pengaruh variabel lain yang tidak diteliti dalam penelitian ini. Dengan demikian variabel Online Customer Review dan Kepercayaan berpengaruh positif dan signifikan Terhadap Minat Beli pada Marketplace Lazada. 


\section{Referensi :}

Arbaini, P. (2020). Pengaruh Consumer Online Rating Dan Review Terhadap Keputusan Pembelian Pada Pengguna Marketplace Tokopedia. Jurnal Bisnis Dan Manajemen, 7(1), 25-33. https://doi.org/10.26905/jbm.v7i1.3897

Ichsan, M., Jumhur, H. M., Hum, M., \& Dharmoputra, I. S. (2018). PENGARUH CONSUMER ONLINE RATING AND REVIEW TERHADAP MINAT BELI KONSUMEN PADA MARKETPLACE TOKOPEDIA DI WILAYAH DKI JAKARTA EFFECT OF CONSUMER ONLINE RATING AND REVIEW TO BUYING. 5(2), 1828-1835.

Khotimah, K., \& Febriansyah, F. (2018). Pengaruh kemudahan penggunaan, kepercayaan konsumen dan kreativitas iklan terhadap minat beli konsumen online-shop. Jurnal Manajemen Strategi Dan Aplikasi Bisnis, 1(1), 19-26. https://doi.org/10.36407/jmsab.v1i1.16

Sri Damayanti, R. (2019). Pengaruh Online Customer Review and Rating, Eservice Quality Dan Price Terhadap Minat Beli Pada Online Marketplace Shopee.

Sugiyono. (2017). Metode Penelitian Kuantitatif, Kualitatif dan R\&D (cetakan 25). Alfabeta.

Tilaar, F., Roring, F., Ekonomi, F., \& Manajemen, J. (2018). SHOPPE SECARA ONLINE PADA ANGGOTA PEMUDA GMIM ZAITUN MAHAKERET THE INFLUENENCE OF TRUST AND MOTIVATION TO USERS SHOPPE INTEREST IN BUYING ONLINE FOR THE MEMBERS OF THE YOUTH GMIM ZAITUN MAHAKERET. 6(4), 2028-2037.

\section{Sumber Website :}

https://databoks.katadata.co.id/ (diakses pada tanggal 11 Februari 2021 pukul 21.54 WIB)

https://www.google.com/amp/s/mediakonsumen.com/2020/02/10/surat-pembaca/lazadatempat-para-penipu/amp (diakses pada Tanggal 17 Maret 2021, Pukul 21:00 WIB)

https://inet.detik.com/security/d-5078857/cerita-korban-penipuan-di-lazada-uang-jutaanmelayang (diakses pada Tanggal 17 Maret 2021, Pukul 21:00 WIB)

https://iprice.co.id/insights/mapofecommerce/ (diakses pada 12 Februari 2021, Pukul 20:45 WIB) 